\title{
Review on the Methods for Measuring the Moisture Content of Green Sand
}

\author{
GAO Guili \\ College of Material Science and \\ Engineering \\ Harbin University of Science \& \\ Technology \\ Harbin, P. R. China \\ gao-guili@163.com
}

\author{
SHI Dequan \\ College of Material Science and \\ Engineering \\ Harbin University of Science \& \\ Technology \\ Harbin, P. R. China \\ shidequan2008@163.com
}

\author{
DONG Jingwei \\ School of Measurement and \\ Communications Engineering \\ Harbin University of Science \& \\ Technology \\ Harbin, P. R. China \\ djw@hrbust.edu.cn
}

\begin{abstract}
The moisture of green sand mainly refers to the water that can be got rid of at the temperature of $105^{\circ} \mathrm{C}-110^{\circ} \mathrm{C}$, and it is affecting sand quality, one of the most important and sensitive parameters that affect the quality of green sand. At present, the methods for measuring the moisture content can be divided into two categories of direct and indirect methods. The precision of the direct method is high while the measurement period is long, so it does not suits to online measurement, and is often used to calibrate the indirect methods. In the indirect methods, the moisture content can be online obtained by measuring the physical parameters or performance indexes related to the moisture. They mainly include the resistance method, capacitance method, inductive method, microwave method, infrared spectrometry method, and nuclear magnetic resonance method.
\end{abstract}

Keywords-Moisture content; Measurement method; green sand

\section{INTRODUCTION}

The green sand casting is an important and main kind of casting method because of the simple process, low cost and high productivity [1]. The green sand is composed of quartz sand, clay, water and additives, and the water is one of the most important and sensitive parameters affected the quality of green sand. Therefore, accurate and rapid measurement of the moisture content is of great significance for enhancing the quality of the castings, improving the production efficiency and promoting the foundry industry automation [2, 3]. On one hand, it is the basis of ensuring the permeability, compactability, green strength and toughness to meet the requirements; On the other hand, it is the premise of realizing the automatic preparation and online control of green sand.

The moisture of green sand mainly refers to the unbound water and part of weak physical bonding water that can be got out when heated at $105^{\circ} \mathrm{C}-110^{\circ} \mathrm{C}$ [4]. At present, there are many methods for measuring the moisture content of green sand, and they can be divided into two categories of direct method and indirect method. In the direct method, the absolute moisture content can be measured by heat or chemical reaction. For the indirect method, the moisture content is obtained by measuring the physical parameters or performance indexes related to the moisture [5]. In general, the direct method has high precision but long measurement

This This work was supported by National Natural Science Foundation of China (51105121), Natural Science Foundation of Heilongjiang (E050801) and the China Postdoctoral Science Foundation (2011044447). period, so it is only suitable for laboratory while unsuitable for the production line. Although the precision of the indirect method is not as high as the direct method, it can be used for online measuring the moisture content of green sand due to the fast speed.

\section{Direct MeAsurement Methods}

\section{A. Weighing Method}

Weighing method is a standard method for measuring the moisture content of green sand. The process is as follows. Firstly, a measurement sample of the green sand is accurately weighed at room temperature, and usually it is 10 gram. Secondly, at the temperature of $105^{\circ} \mathrm{C}-110^{\circ} \mathrm{C}$, the sample is heated for an hour in a special oven. Thirdly, the sample is pulled out and cooled down to the room temperature in a dried container and is weighed by scale. Then, the sample is heated for 10 minutes, cooled and weighed again. When the weight difference between successive two times is less than 0.002 gram, the measurement is finished, and the moisture content of green sand can be got by the ratio of the final mass and the original mass.

To shorten the heating and cooling time, the infrared heat is often used and the measurement result can be given in a few minutes.

The weighing method has high accuracy but longer measuring period, so it can not be used for the online measurement and control during the casting production. In addition, some substances in green sand may evaporate when heated, which will impact on the measurement accuracy to some degrees [6].

\section{B. Calcium Carbide Decomposition Method}

In this method, the moisture content of green sand is achieved according to the decomposition of calcium carbide. The chemical reaction equation is as follows.

$$
\mathrm{CaC}_{2}+2 \mathrm{H}_{2} \mathrm{O}=\mathrm{Ca}(\mathrm{OH})_{2}+\mathrm{CH}_{2} \uparrow
$$

We can conclude that the amount of the generated acetylene is proportional to the moisture content of green sand. Before experimented, the calcium carbide and appropriate 
green sand are put into the measurement cylinder which is connected to the pressure gauge. During the measurement, we shake the cylinder so that the chemical reaction can be entirely done. When the pressure gauge keeps stable, we can read out the pressure. According to this pressure, the moisture content of green sand can be got [7].

The disadvantage of this method is less representative sample. In addition, the potential incomplete reaction will increase the measurement error.

\section{InDiRECT MEASUREMENT MEthodS}

\section{A. Resistance Method}

Resistance method is the first electrical measuring method used in green sand, and it includes DC resistance method and AC impedance method [8]. The measurement basis is that the resistance or impedance differs when the moisture content is different. Experiments show that the moisture content of green sand has a logarithmically linear relationship with its resistance at the fixed range, and that the higher the moisture content is, the smaller the resistance is.

Fig. 1 shows the schematic map of measuring the moisture content by resistance method [9]. One pole is the moisture probe inserted in the green sand, and the other is the side wall of the sand mixer. After a voltage supply is applied to the circuit, the voltage between these two poles is measured. The moisture content of green sand can be obtained by looking up the pre-stored voltage-moisture curve according to the measured voltage. The temperature probe is used to the temperature compensator, correcting the voltage change caused by the temperature fluctuation of green sand.

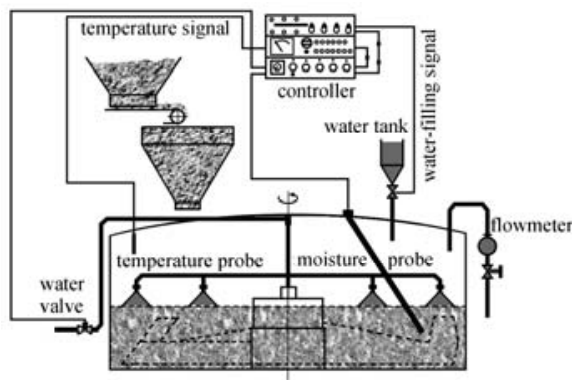

Figure 1 Schematic map of measuring moisture content by resistance method

Literature [10] gives an example of moisture measurement by resistance method. First, the curve between the conductivity and the moisture content is drew out by experiments and stored in computer. Then, during measurement the conductivity is got by $\mathrm{A} / \mathrm{D}$ converter, and thus the moisture content is calculated by automatic lookup and interpolation operation. The MIC moisture content tester is constructed according to AC impedance method, and is used to measure the moisture content of the recycling sand. Also, the thermocouples installed on the conveyor belt are used to measure the sand temperature.

The resistance method has been applied in foundry. However, the resistance of green sand relates to the composition, the temperature, the compactability, the bonding type, the additive type, and the binding mode of the water, especially the clay content. So the accurate moisture content can be obtained only when the designated types of green sand are measured.

\section{B. Capacitance Method}

In the capacitance method, the moisture content is measured according to the fact that the dielectric constant of green sand has the single-valued relationship with the moisture but without the other components [11]. This method has high sensitivity to the moisture and can be used for the continuous measurement of the production line. To reduce the influence of the resistance derived from the leakage conductance, the high-frequency AC power is usually employed, or the resistance and capacitance of green sand are measured simultaneously.

Germany FS-2 green sand device is a typical example of measuring the moisture content by the capacitance method. The sensors installed on the mixer and the cooler are used to the measurement and control for the moisture [12]. In Dieter green sand automatic moisture controller, the needle-shaped capacitance sensor is made of stainless steel, and mounted inside the sand mixer.

The capacitance method is greatly affected by the temperature and the packing density of green sand, especially for high moisture content. The higher the moisture is, the better the conductive capacity is. The green sand may change from the insulator into the conductor, and the capacitance becomes saturated. Therefore, the moisture content is unable to be measured due to the unchanged capacitance. Experiments show that the maximum of the moisture is 3.5\% for the capacitance method. In order to extend the measurement range, the super high-frequency capacitance sensor can be used, and the calculation formula of its complex impedance is as follows.

$$
Z=\frac{1}{1 / R+2 \pi f C}
$$

where, $Z$ is the complex impedance, $R$ is the resistance, $C$ is the capacitance, and $f$ is the frequency.

It can be seen that the influence of the resistance $R$ becomes weak with the increase of the frequency $f$. The measurement maximum of the moisture is over $10 \%$ when the frequency is increased to $30 \mathrm{MHz}$. The super high-frequency sensor has been developed.

\section{Inductance Method}

The principle of the inductance method is as follows. The magnetic conductivity coefficient of water is much greater than other components of green sand, so the inductance of the sand-filled coil will improve with the increase of the moisture content. When the moisture content does not exceed $15 \%$, the output voltage derived from the inductance shows an approximate linear relationship with the moisture [13]. Accordingly, the moisture content of green sand can be calculated by the inductance change. 
The component and temperature of green sand are found to have small effect on the inductance method. The probe can be directly inserted in green sand, also can be mounted on the mixer for continuous measurement. However, the inductance method is affected by the compactness, and high-frequency oscillator has to be used to avoid the generation of the eddy

\section{Microwave Method}

When super high-frequency electromagnetic waves (300MHz-300GHz) pass through the green sand with different moisture content, the energy loss, phase shift and wave parameters will differ, which is the principle of microwave method [14]. The practical microwave method includes the resonant cavity method, reflection method and transmission method, and the last one is widely used to measure the moisture content.

The dielectric characteristic, including the dielectric constant and dielectric loss, of water is much bigger than the others. According to the relationship of the electromagnetic energy, the energy attenuation $W$ of super high-frequency electromagnetic waves can be described as:

$$
W=8.68 \alpha_{B} M \rho k t+|\tau|-|\tau| e^{-2 \alpha_{B} t} \cos 2 B t
$$

where, $M$ is the moisture content, $\rho$ is the density, $k$ is material factor, $|\tau|$ is the modul of reflection coefficient between air and green sand, $\alpha_{B}$ is the damping coefficient of water, $t$ is the thickness of green sand, and $B$ is the number of phases of aqueous materials.

When the thickness $t$ is large enough, the moisture content of green sand can be written as:

$$
M=\frac{W-|\tau|}{8.68 \alpha_{B} \rho k t}
$$

The microwave method has high sensitivity, accuracy and measurement speed. The measurement is not affected by the salt compounds and colored substances of green sand. Therefore, it is suitable to measure the moisture from 0 to $10 \%$.

The green sand is a kind of multiphase dielectric material, and the moisture measurement accuracy is affected by the flow state. Therefore, to eliminate the influence of the density change, the attenuation and the phase shift during microwave propagation are required to be measured simultaneously [15]. In recent years, the two-parameter measurement techniques effectively eliminate the influence, which further improves the application of the microwave method in green sand.

\section{E. Infrared Spectrometry Method}

It is well known that every substance can absorb one or several fixed wavelength spectra. Water has a strong absorption on infrared spectrum with the wavelength of 1.94um [16]. Therefore, the infrared absorption of green sand will change with the moisture.

The infrared is hardly to transmit into the green sand in that it is solid particulate and with certain compactness, so only infrared diffuse reflection method can be used to measure the surface moisture content. To avoid the effect of thickness and density, two kinds of infrared with the wavelengths of 1.94um and 1.81um are taken as the measuring and reference beam, respectively [17]. Here, the moisture is not sensitive to the 1.81um-wavelength infrared. Fig. 2 shows a schematic diagram of measuring the moisture content by the infrared reflection method.

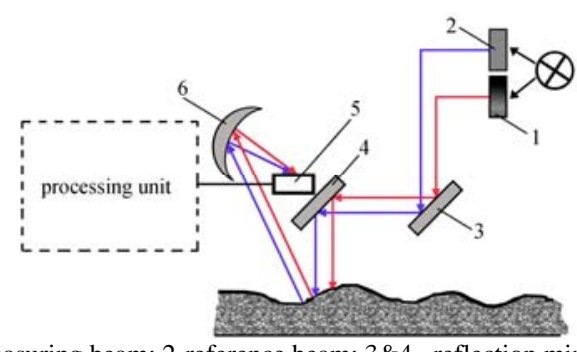

1-measuring beam; 2-reference beam; 3\&4 -reflection mirrors; 5photoelectric receiver; 6-converging mirror

Figure 2 Schematic diagram of measuring moisture content by infrared reflection method

When the beams are projected on green sand, the measuring beam is partly reflected because of the absorption by green sand while the reference beam is entirely reflected back to the to the paraboloid-shaped converging mirror. The two reflected infrared beams are collected by the photoelectric receiver and converted into electrical signals, and then by calculation of the processing unit the moisture content of green sand is given.

The temperature and density of green san have little effect on the infrared spectrometry method, and the moisture measurement range is without restriction. But it is affected by the granularity and used to measure the surface moisture of green sand.

\section{F. Performance Parameter Method}

Some performance parameters of green sand, such as the compactability, moldability and bulk density, closely correlate to the moisture content. Therefore, we can also get the moisture content by measuring these parameters. This method is suitable for online continuous measurement, and has achieved some certain applications in foundry. But most of the measuring devices are mechanical and their structure is complex.

The literature [18] gives a moisture controller based on the successive measurement for compactability. By comparing the compactability between the measured and the set values, the controller can draw the time and the mount of filling water.

The moldability is an index of indicating the process that the green sand gradually transits from the scattered state into the viscous state with the increase of the moisture content. The literature [19] shows a water-filling control system based on the moldability. First, a certain amount of water is preadded and the green sand is mixed uniformly. Second, the mixed green sand is transported to the vibrator with two slots that one is large and the other is small. Then, according to the status of green sand dropping out of slots, the moldability can 
be got and fed back to the water-filling system. The biggest drawback of this system is that the precision is very low when the moisture fluctuation of used sand is large.

\section{G. Neutron method}

The principle of the neutron method is as follows. When the fast neutrons from the neutron source (AmericiumBeryllium or Radium-Beryllium) collide with the hydrogen nuclei of water, their speed will slow down. The more the water is, the more the quantity of the slow neutrons is. There is a linear relationship between the quantity of slow neutrons and the moisture content of green sand. Therefore, the moisture content can be obtained by the quantity of slow neutrons [20].

The neutron method can be used for measuring a large volume of green sand. The quantity of slow neutrons is not affected by the clay and sand thickness, but is affected by the compactness. In addition, the security measures must be taken because of the radioactivity.

\section{H. Nuclear magnetic resonance method}

When the frequency of the alternating magnetic field applied to green sand is equal to the Larmor frequency of the hydrogen nuclei, all of the hydrogen nuclei will form a synthetic magnetic moment, and thus an alternating current proportional to the moisture will be generated in the coil [21]. This is the nuclear magnetic resonance method, and the moisture content can be calculated by the current.

The advantage of this method lies in avoiding the influence of the density and temperature, but it is expensive and complicated. At present, it is still at the experimental stage.

\section{SUMMARY}

The moisture content is one of the most important parameters that affect the green sand performance and thus the casting quality. The measurement for the moisture content of green sand is a comprehensive and multi-disciplinary technology. The direct method for measuring the moisture content is accurate but slow, which is unsuitable to online measurement and control, and used for calibrating other measurement methods. The indirect method is mainly used for online measuring the moisture. The resistance method, capacitance method and inductance method have applied in casting production to some degree. However, because these methods are developed to measure the moisture content based on the dielectric coefficient, they are susceptible to many factors. With the development of computer technology, the microwave method is paid more and more attention and is gradually used in casting production. As a noncontact method, the infrared spectrometry is not affected by the temperature, density and measurement range, but it can only measure the surface moisture content. Although the performance parameter method based on the compactablity and moldability measurement has been used, the precision need to be improved. Because of potential radioactive danger the neutron method is rarely used. The nuclear magnetic resonance method is still at the experimental stage.

\section{REFERENCES}

[1] J. M. Beaman, J. F. Cuttino, and E. P. Morse, "Parameter influence on dimensional variation in green sand iron castings," AFS Transactions, vol. 115, pp. 349-366, February 2007.

[2] R. L. Beaman, "The sand controversy: Does core sand harm your green sand?” Modern casting, vol. 94, pp. 34-37, May 2004.

[3] S. S. M. Nazirudeen, and B. Nagasivamuni, "Improving the quality of green sand castings to minimise the defects using artificial neural network,” Indian Foundry Journal, vol. 58, pp. 32-37, February 2012.

[4] S. G. Baker, "Building the foundation for green sand," Modern Casting, vol. 95, pp. 26-29, August 2005.

[5] M. Fukihara, Y. Makino, and K. Hashimoto, "Automation technology in green sand processing equipment,” Journal of Japan Foundry Engineering, vol. 81, pp. 504-508, October 2009.

[6] B. Surekha, L. K. Kaushik, A. K. Panduy, P. R. Vundavilli, and M. B. Parappagoudar, "Multi-objective optimization of green sand mould system using evolutionary algorithms," The International Journal of Advanced Manufacturing Technology, vol. 58, pp. 9-17, January 2012.

[7] S. Chen, J. Hu, and S. Zhu, "A review of development of mould sand moisture measuring and controlling instruments," Neural Networks, no. 3, pp. 47-51, March 2001.

[8] M. B. Parappagoudar, D. K. Pratihar, and G. L. Datta, "Linear and nonlinear statistical modelling of green sand mould system,” International Journal of Cast Metals Research, vol. 20, pp. 1-13, January 2007.

[9] S. Guharaja, H. A. Noorul, and K. M. Karuppannan, "Optimization of green sand casting process parameters by using Taguchi's method,” The International Journal of Advanced Manufacturing Technology, vol. 30, pp. 1040-1048, October 2006.

[10] Y. Lin, and W. Wang, "Design of intelligent on-line measuring system of moisture content in moulds sand,” Foundry, vol. 54, pp. 1011-1013, October 2005.

[11] H. R. Xiao, and W. W. Zhang, "Intelligent moisture controlling system for molding sand,” Advanced Materials Research, vol. 97-101, pp. 4309-4312, March 2010.

[12] S. Joyce, M.Ziegler, and V. F. La, "Optimizing new sand and core sand additions in foundry green sand systems," Foundry Management and Technology, vol. 133, pp. 46-47, August 2005.

[13] H. Bidadi, P. A. Schroeder, and J. P. Thomas, "Dielectric properties of montmorillonite clay films: effects of water and layer charge reduction," Journal of Physics and Chemistry of Solids, vol. 49, pp. 1435-1440, December 2002.

[14] Z. Li, Z. Huang, Y. Huang, and S. Deng, "Design of microwave moisture measuring instrument," Transactions of the Chinese Society of Agricultural Machinery, vol. 40, pp. 81-83, February 2009.

[15] Y. Zhang, C. Zheng, and Z. Hu, "Investigation on the main technology for measuring moisture in molding sand,” Foundry Technology, vol.27, pp. 1137-1140, October 2006.

[16] C. Paluszkiewicz, M. Holtzer, and A. Bobrowski, "FTIR analysis of bentonite in moulding sands," Journal of Molecular Structure, vol. 880, pp. 109-114, september 2007.

[17] D.Shi, G. Gao, D. Li, J. Dong, and Z. Gao, "Review on measurement techniques for composition and performance parameters of green sand," Journal of Harbin University of Science and Technology, vol. 16, pp.7782, December 2011.

[18] H. Xiao, Y. Fu, and M. Chai, “A High-Accuracy Intelligent Controlling System for Molding Sand Moisture,” Foundry, vol. 58, pp. 259-261, March 2009.

[19] J. Gu, and S. Zhu, "Review on the moisture measuring for molding sand,” Journal of China Textile University, vol.24, pp. 115-118, October 1998.

[20] F. Yang, S. Zhu, Z. Fu, and C. Ji, "Present situation of automatic measurement and quality control of green sand," Journal of Donghua University, vol. 32, pp. 130-134, April 2006.

[21] L. Pel, H. Brocken, and K. Kopinga, "Determiination of moisture diffusivity in porous media using moisture concentration profiles," International Journal of Heat and Mass Transfer, vol. 39, pp. 1273-1280, April 1996. 